\title{
Research Paper: Is Obesity a Risk Factor for Spinal Surgeries? A Retrospective Study in a Specialized Orthopedic Spine Center
}

\author{
Hasan Ghandhari $^{1}$ (D, Ebrahim Ameri ${ }^{1}$, Mohsen Motalebi ${ }^{*}$, Mohamad Mahdi Azizi ${ }^{1}$ (D)
}

1. Bone and Joint Reconstruction Research Center, Shafa Orthopedic Hospital, Iran University of Medical Sciences, Tehran, Iran

Citation Ghandehari H, Ameri E, Motalebi M, Azizi MM. Is Obesity a Risk Factor for Spinal Surgeries? A Retrospective Study in a Specialized Orthopedic Spine Center. Journal of Research in Orthopedic Science. 2021; 8(1):37-42. http://dx.doi. org/10.32598/JROSJ.8.1.759.1

http://dx.doi.org/10.32598/JROSJ.8.1.759.1

Keywords:

Obesity, Spine surgery, Complications

\begin{abstract}
A B S T RA C T
Background: Various studies have shown the effects of morbid obesity on the adverse consequences of various surgeries, especially postoperative infections. However, some studies have shown that the complications of spinal surgery in obese and non-obese patients are not significantly different.

Objectives: This study investigated and compared the duration of surgery, length of hospital stay, and complications after common spinal surgeries by orthopedic spine fellowship in obese and non-obese patients in a specialized spine center in Iran.

Methods: All patients who underwent decompression with or without lumbar fusion were included in this retrospective study. These patients were classified into two groups: non-obese $\left(B M I<30 \mathrm{~kg} / \mathrm{m}^{2}\right.$ ) and obese (BMI $\geq 30 \mathrm{~kg} / \mathrm{m}^{2}$ ). The data related to type and levels of surgery, 30 day hospital complications, length of hospital stay, rate of postoperative wound infection, blood loss, and need for transfusion were all extracted and compared between the two groups.

Results: A total of 148 patients (74\%) were in the non-obese group and 52 patients (26\%) in the obese group. The number of patients that need packed cells was significantly higher in the obese group $(51.8 \%$ vs $32.6 \%)(\mathrm{P}=0.01)$. Otherwise, there were not a significant difference between type of treatment (fusion or only decompression) $(\mathrm{P}=0.78)$, interbody fusion $(\mathrm{P}=0.26)$, osteotomy $(\mathrm{P}=0.56)$, duration of surgery $(\mathrm{P}=0.25)$, length of hospital stay $(\mathrm{P}=0.72)$, mean amount of blood loss $(\mathrm{P}=0.09)$, and postoperative complications $(\mathrm{P}=0.68)$ between the two groups.
\end{abstract}

Conclusion: Our results suggest that duration of surgery, length of hospital stay, and postoperative complications are not associated with the BMI of the patients.

\footnotetext{
* Corresponding Author:

Mohsen Motalebi, PhD.

Address: Bone and Joint Reconstruction Research Center, Shafa-Yahyaian hospital, Baharestan Square, Tehran, Iran.

Phone: +98 (919) 2388928

E-mail:dr.motalebi@ymail.com
} 


\section{Introduction}

$\mathrm{n}$ the United States and other developed countries, morbid obesity has been rising over the

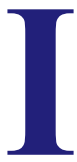
past decade [1]. Of all its related effects, increased incidence of low back pain and spinal degeneration have been reported abundantly. Degenerative disorders due to obesity are mainly observed in the lumbar region [2,

3]. Besides, various studies have reported the effects (especially postoperative infections) of morbid obesity on the adverse outcomes of heart and other surgeries [4, 5]. Along with the increasing prevalence of morbid obesity, referrals to orthopedic surgeons for the management and treatment of degenerative lumbar spine diseases have significantly increased and are associated with increased health care costs. According to some studies, the total cost of surgery for obese patients referred for arthrodesis is estimated to be about $27 \%$ higher than that for nonobese patients [6]. The increase in hospital costs in these patients was mainly due to the higher complications after surgery and also the longer duration of hospitalization in obese patients compared to non-obese ones [6]. However, some studies have shown that the complications of spinal surgery in obese and non-obese patients were not statistically significant $[7,8]$.

The present study investigated and compared the duration of surgery, length of hospital stay, and short-term complications after common lumbar surgery in obese and non-obese patients in a specialized spine center by the orthopedic spine fellowship in Iran.

\section{Patients and Methods}

All patients who underwent lumbar decompression surgery with or without fusion in Shafa-Yahyaian Medical Center in 2018 and whose files were complete were included in this retrospective study. All surgeries were performed by the orthopedic spine fellowship. The patients' information, including age, gender, height, weight, and Body Mass Index (BMI), were extracted from their records. According to the World Health Organization definition of obesity, the patients were classified into two groups: non-obese (BMI $\left.<30 \mathrm{~kg} / \mathrm{m}^{2}\right)$ and obese $\left(B M I \geq 30 \mathrm{~kg} / \mathrm{m}^{2}\right)$. Through reviewing the archive file, information about the type and level of surgery, 30day complications and mortality, length of hospital stay, postoperative wound infection, fusion levels, blood loss, and the need for transfusion were all extracted and compared between the two groups.
Superficial and deep infections were evaluated clinically and during the irrigation surgery. Other complications such as deep vein thrombosis, pulmonary thromboembolism, myocardial infarction, intra-abdominal bleeding, and atelectasis were also extracted.

\section{Statistical analysis}

All stages this descriptive-analytical study were conducted in SPSS v. 16 software using the Chi-square and Independent Samples t-test. P-values less than 0.05 were considered statistically significant.

\section{Results}

A total of 200 patients with a Mean \pm SD age of $51.51 \pm 16.27$ years and a Mean \pm SD BMI of 27.84 \pm 5.13 $\mathrm{kg} / \mathrm{m}^{2}$ were included in the study. Also, 131 patients $(65.5 \%)$ were female, and the rest were male. Out of 200 patients, 52 underwent decompression alone, and 148 underwent fusion. Of them, $53.2 \%$ had a fusion at one or two levels, $17.5 \%$ at 3 or 4 levels, and the rest more than 4 levels. In 43 cases $(21.5 \%)$, the interbody fusion with the cage was performed. Table 1 presents the information for the two groups. In the obese group, 29 patients $(51.8 \%)$ and in the non-obese group, 47 patients $(32.6 \%)$ required blood transfusion $(\mathrm{P}=0.01)$. The Mean $\pm \mathrm{SD}$ duration of surgery was $4.66 \pm 1.52$ and $4.38 \pm 1.58 \mathrm{~h}$ in obese and non-obese groups $(\mathrm{P}=0.25)$. Also, the length of hospitalization was $7.93 \pm 4.66$ and $8.26 \pm 6.27$ days in the two groups, respectively $(\mathrm{P}=0.72)$. The relationships between obesity and other variables are presented in Table 2.

\section{Discussion}

Obesity is prevalent among patients undergoing orthopedic surgery, including spine surgery [7]. In general, patients with higher BMI have thicker subcutaneous tissue, which leads to a longer duration of surgery [8]. Also, more bleeding is probably due to the longer surgery time [9-11]. However, some studies show that the complications of spinal surgery and the length of hospital stay of obese and non-obese patients are not significantly different. Therefore, the relationship between obesity and complications of spinal surgeries is a controversial issue. This study aimed to evaluate and compare complications during and after surgery in obese and non-obese patients who have undergone spine surgery in a specialized spine center by orthopedic spine fellowship.

In this retrospective study, there was no significant difference between obese and non-obese patients in superficial and deep postoperative infections. Also, the length 
Table 1. Comparison of variables in obese and non-obese groups

\begin{tabular}{|c|c|c|c|c|}
\hline \multirow{2}{*}{\multicolumn{2}{|c|}{ Variables }} & \multicolumn{2}{|c|}{ Mean $\pm S D /$ No. (\%) } & \multirow{2}{*}{$\mathbf{P}$} \\
\hline & & Obese Patients, $\mathrm{n}=52$ & Non-obese Patients, $\mathrm{n}=148$ & \\
\hline & & $55.23 \pm 11.20$ & $50.06 \pm 17.70$ & 0.02 \\
\hline \multirow{3}{*}{ Gender } & Male & $10(17.9)$ & $59(41)$ & \multirow{3}{*}{0.00} \\
\hline & & & & \\
\hline & Female & $46(82.1)$ & $85(59)$ & \\
\hline \multirow{3}{*}{ Type of surgery } & Decompression only & $15(26.8)$ & $37(25.7)$ & \multirow{3}{*}{0.78} \\
\hline & & & & \\
\hline & Fusion & $41(73.2)$ & $107(74.3)$ & \\
\hline \multicolumn{2}{|c|}{ Interbody fusion } & $15(26.8)$ & $28(19.4)$ & 0.26 \\
\hline \multicolumn{2}{|c|}{ Osteotomy } & $2(3.6)$ & $8(5.6)$ & 0.56 \\
\hline
\end{tabular}

Table 2. Comparison of during and postoperative outcomes between obese and non-obese groups

\begin{tabular}{|c|c|c|c|}
\hline \multirow{2}{*}{ Variables } & \multicolumn{2}{|c|}{ Mean \pm SD/ No. (\%) } & \multirow{2}{*}{$\mathbf{P}$} \\
\hline & Obese Patients, $n=48$ & Non-obese Patients, $n=152$ & \\
\hline Duration of surgery (h) & $4.66 \pm 1.52$ & $4.38 \pm 1.58$ & 0.25 \\
\hline Length of hospitalization (d) & $7.93 \pm 4.66$ & $8.26 \pm 6.27$ & 0.72 \\
\hline Blood loss (mL) & $808.93 \pm 438.54$ & $723.17 \pm 395.24$ & 0.09 \\
\hline Requires transfusion & $29(51.8)$ & $47(32.6)$ & 0.01 \\
\hline Superficial infection & $1(1.8)$ & $1(0.7)$ & 0.74 \\
\hline Deep infection & $0(0)$ & $2(1.4)$ & 0.68 \\
\hline Other complications & $2(3.6)$ & $5(3.5)$ & 0.81 \\
\hline
\end{tabular}

of hospitalization and the duration of surgery were not different between the two groups. These findings were consistent with some other studies $[10,12]$. A study by Giannadakis et al. [13] showed no difference between the two groups in terms of postoperative complications ( $10.4 \%$ vs $10.8 \%$ in the non-obese and obese groups) and length of hospital stay (2.7 days vs 3 days). However, surgery duration in non-obese patients was significantly shorter than that in obese patients (104 min compared to $114 \mathrm{~min})$. However, other studies have emphasized the role of obesity in increasing complications and length of hospital stay [7, 14, 15]. In another study by Onyekwelu et al., the rate of blood loss and surgery duration in nonobese people was much lower than in obese people [16]. Obese patients also had significantly longer hospital stays (4.1 days vs 3.3 days). In our study, the mean blood loss was more in the obese group, although this increase was not significant $(\mathrm{P}=0.09)$. However, the number of patients that need packed cells was significantly higher in the obese group (51.8\% vs $32.6 \%)$. This finding is probably due to preoperative anemia in obese patients, reported by various studies $[17,18]$. In this regard, one of the limitations of the current study is the lack of evaluation of patients' hemoglobin before surgery. This finding indicates the need to evaluate hemoglobin and correct it before surgery in obese patients.

Many researchers have suggested that obesity is associated with poor prognosis and adverse outcomes that increase the risk of surgical complications [9, 19-22]. Obese patients have thicker subcutaneous adipose tissue that causes dead tissue after surgical wound healing. Therefore, local fat necrosis can cause local infections [8, 22]. Besides, this subcutaneous tissue layer can increase the risk of complications such as surgical site infection or wound complications by potentially creating a dead space after closure [23]. However, factors such as prophylactic antibiotics and precise sterility are effective in 
reducing infection and surgical outcomes [24]. It seems that the observance of sterilization is one of the essential principles in orthopedics (due to multiple surgeries on the bone and bone implantation and the high risk of bone infection). Spine surgery by orthopedic spine fellowship should not be ineffective in reducing complications in obese patients. Therefore, according to the authors, precise sterilization, use of prophylactic antibiotics, preoperative site preparation since the night before surgery, and the speed of surgery will be more effective in the surgical results than the obesity factor.

We had some limitations in doing this study. First, this study was performed retrospectively. Second, the number of our patients was lower than other similar studies. Third, in this study, we placed a BMI above $30 \mathrm{~kg} / \mathrm{m}^{2}$ in the obese group due to the low number of patients. In contrast, many studies compared the complications in the morbid obesity group, which typically has a BMI above $40 \mathrm{~kg} / \mathrm{m}^{2}$.

\section{Conclusion}

The present study results showed that in the obese and non-obese patients, superficial and deep postoperative infections are the same and do not differ. In general, the operation's outcome (duration of surgery and duration of hospitalization) and postoperative complications (superficial infection, deep infection, etc.) are not related to BMI.

\section{Ethical Considerations}

\section{Compliance with ethical guidelines}

The study was approved by the National Research Ethics Committee of Iran University of Medical Sciences. IR.IUMS.FMD.REC 1396.9311286010

\section{Funding}

This study is self-funded

\section{Authors' contributions}

Study design, drafting the manuscript, and final supervision: Hasan Ghandehari; Conception and design, editing, and final supervision: Ebrahim Ameri; Data collection, drafting the manuscript, statistical analysis, and writing the manuscript: Mohsen Motalebi; Data collection: Mohamad-mahdi Azizi.

\section{Conflict of interest}

The authors declared no conflict of interest

\section{References:}

[1] Freedman DS, Khan LK, Serdula MK, Galuska DA, Dietz WH. Trends and correlates of class 3 obesity in the United States from 1990 through 2000. JAMA. 2002; 288 (14):175861. [DOI:10.1001/jama.288.14.1758] [PMID]

[2] Hangai M, Kaneoka K, Kuno S, Hinotsu S, Sakane M, Mamizuka N, et al. Factors associated with lumbar intervertebral disc degeneration in the elderly. Spine J. 2008; 8 (5):732-40. [DOI:10.1016/j.spinee.2007.07.392] [PMID]

[3] Liuke M, Solovieva S, Lamminen A, Luoma K, Leino-Arjas $\mathrm{P}$, Luukkonen $\mathrm{R}$, et al. Disc degeneration of the lumbar spine in relation to overweight. Int J Obes (Lond). 2005; 29 (8):9038. [DOI:10.1038/sj.ijo.0802974] [PMID]

[4] Dindo D, Muller MK, Weber M, Clavien PA. Obesity in general elective surgery. Lancet. 2003; 361 (9374):2032-5. [DOI:10.1016/S0140-6736 (03)13640-9] [PMID]

[5] Moulton MJ, Creswell LL, Mackey ME, Cox JL, Rosenbloom M. Obesity is not a risk factor for significant adverse outcomes after cardiac surgery. Circulation. 1996; 94 (suppl 9):II87-92. [PMID]

[6] LaCaille RA, DeBerard MS, LaCaille LJ, Masters KS, Colledge AL. Obesity and litigation predict workers' compensation costs associated with interbody cage lumbar fusion. Spine J. 2007; 7(3):266-72. [DOI:10.1016/j.spinee.2006.05.014] [PMID]

[7] Jiang J, Teng Y, Fan Z, Khan S, Xia Y. Does obesity affect the surgical outcome and complication rates of spinal surgery? A meta-analysis. Clin Orthop Relat Res. 2014; 472(3):968-75. [DOI:10.1007/s11999-013-3346-3] [PMID] [PMCID]

[8] Mehta AI, Babu R, Karikari IO, Grunch B, Agarwal VJ, Owens TR, et al. 2012 Young Investigator Award winner: The distribution of body mass as a significant risk factor for lumbar spinal fusion postoperative infections. Spine. 2012; 37(19):16526. [DOI:10.1097/BRS.0b013e318241b186] [PMID]

[9] Senker W, Meznik C, Avian A, Berghold A. Perioperative morbidity and complications in minimal access surgery techniques in obese patients with degenerative lumbar disease. Eur Spine J. 2011; 20(7):1182-7. [DOI:10.1007/s00586011-1689-6] [PMID] [PMCID]

[10] Hardesty CK, Poe-Kochert C, Son-Hing JP, Thompson GH. Obesity negatively affects spinal surgery in idiopathic scoliosis. Clin Orthop Relat Res. 2013; 471(4):1230-5. [DOI:10.1007/s11999-012-2696-6] [PMID] [PMCID]

[11] Rihn JA, Radcliff K, Hilibrand AS, Anderson DT, Zhao W, Lurie J, et al. Does obesity affect outcomes of treatment for lumbar stenosis and degenerative spondylolisthesis? Analysis of the Spine Patient Outcomes Research Trial (SPORT). Spine. 2012; 37(23):1933. [DOI:10.1097/ BRS.0b013e31825e21b2] [PMID] [PMCID]

[12] Peng CW, Bendo JA, Goldstein JA, Nalbandian MM. Perioperative outcomes of anterior lumbar surgery in obese versus non-obese patients. Spine J. 2009; 9(9):715-20. [DOI:10.1016/j.spinee.2009.04.023] [PMID]

[13] Giannadakis C, Nerland US, Solheim O, Jakola AS, Gulati $\mathrm{M}$, Weber C, et al. Does obesity affect outcomes after decompressive surgery for lumbar spinal stenosis? A multicenter, observational, registry-based study. World Neurosurg. 2015; 84(5):1227-34. [DOI:10.1016/j.wneu.2015.06.020] [PMID] 
[14] Kalanithi PA, Arrigo R, Boakye M. Morbid obesity increases cost and complication rates in spinal arthrodesis. Spine. 2012; 37(11):982-8. [DOI:10.1097/BRS.0b013e31823bbeef] [PMID]

[15] Knutsson B, Michaëlsson K, Sandén B. Obesity is associated with inferior results after surgery for lumbar spinal stenosis: A study of 2633 patients from the Swedish spine register. Spine. 2013; 38(5):435-41. [DOI:10.1097/ BRS.0b013e318270b243] [PMID]

[16] Onyekwelu I, Glassman SD, Asher AL, Shaffrey CI, Mummaneni PV, Carreon LY. Impact of obesity on complications and outcomes: A comparison of fusion and nonfusion lumbar spine surgery. J Neurosurg Spine. 2017; 26(2):158-62. [DOI:10.3171/2016.7.SPINE16448] [PMID]

[17] Arshad M, Jaberian S, Pazouki A, Riazi S, Rangraz MA, Mokhber S. Iron deficiency anemia and megaloblastic anemia in obese patients. Rom J Intern Med. 2017; 55(1):3-7. [DOI:10.1515/rjim-2016-0046] [PMID]

[18] Lecube A, Carrera A, Losada E, Hernández C, Simó R, Mesa $\mathrm{J}$. Iron deficiency in obese postmenopausal women. Obesity. 2006; 14(10):1724-30. [DOI:10.1038/oby.2006.198] [PMID]

[19] Gepstein R, Shabat S, Arinzon Z, Berner Y, Catz A, Folman Y. Does obesity affect the results of lumbar decompressive spinal surgery in the elderly? Clin Orthop Relat Res. 2004; (426):13844. [DOI:10.1097/01.blo.0000141901.23322.98] [PMID]

[20] Patel N, Bagan B, Vadera S, Maltenfort MG, Deutsch $\mathrm{H}$, Vaccaro AR, et al. Obesity and spine surgery: Relation to perioperative complications. J Neurosurg Spine. 2007; 6(4):291-7. [DOI:10.3171/spi.2007.6.4.1] [PMID]

[21] Rosen DS, Ferguson SD, Ogden AT, Huo D, Fessler RG. Obesity and self-reported outcome after minimally invasive lumbar spinal fusion surgery. Neurosurgery. 2008; 63(5):95660. [DOI:10.1227/01.NEU.0000313626.23194.3F] [PMID]

[22] Ter Gunne AFP, Cohen DB. Incidence, prevalence, and analysis of risk factors for surgical site infection following adult spinal surgery. Spine. 2009; 34(13):1422-8. [DOI:10.1097/ BRS.0b013e3181a03013] [PMID]

[23] Stein PD, Beemath A, Olson RE. Obesity as a risk factor in venous thromboembolism. The American Journal of Medicine. 2005; 118(9):978-80. https://www.sciencedirect.com/science/article/abs/pii/S000293430500207X

[24] Basques BA, Bohl DD, Golinvaux NS, Smith BG, Grauer JN. Patient factors are associated with poor short-term outcomes after posterior fusion for adolescent idiopathic scoliosis. Clinical Orthopaedics and Related Research ${ }^{\circledast}$. 2015; 473(1):286-94. https:/ /link.springer.com/article/10.1007/ s11999-014-3911-4 
This Page Intentionally Left Blank 